УДК 553.499:550.4:504.064(571.150)

\title{
РТУТЬ В КОМПОНЕНТАХ ПРИРОДНОЙ СРЕДЫ РЕСПУБЛИКИ АЛТАЙ
}

Робертус Юрий Владимирович1, ariecol@mail.gorny.ru

\author{
Рихванов Леонид Петрович 2 \\ Пузанов Александр Васильевич1, \\ puzanov-aleksander@mail.ru \\ Кац Валентина Елизаровна 3 , \\ altai.geo@yandex.ru \\ 1 Институт водных и экологических проблем СО РАН, \\ Россия, 656038, г. Барнаул, ул. Молодежная, 1. \\ 2 Национальный исследовательский Томский политехнический университет, \\ Россия, 634050, г. Томск, пр. Ленина, 30. \\ 3 АО «Алтай-Гео», \\ Россия, 649100, с. Майма, ул. Заводская, 52.
}

\begin{abstract}
Актуальность работы обусловлена необходимостью обобщения обширной разноплановой инфрормации по экогеохимии ртути в природных средах и техногенных объектах Республики Алтай.

Цель: сбор и систематизация данных по уровням содержания ртути в компонентах природной среды на фроновых и загрязненных территориях региона.

Методы: изучение и анализ опубликованных и фондовых материалов эколого-геохимических работ на ртуть, проведенных в 1980-2020-х г2. научными и производственными организациями на территории Республики Алтай.

Результаты. Приведены сведения об основных природных и антропогенных источниках эмиссии ртути в регионе и уровнях ртутного загрязнения природной среды в зонах их воздействия. Впервые оценены уровни содержания ртути для большого комплекса компонентов природной среды. Показано преобладание в них фоновых концентраций ртути и их тесные связи с горными породами складчатого фундамента. Намечена высотно-поясная зональность в распределении ртути в почвах природных ландшаффтов. Предварительно оценен фон ртути в горных породах и других компонентах природной среды региона. Установлен его слабо повышенный относительно кларков уровень.

Выводы. Геологические образования региона не носят ртутной специализации. Повышенный уровень локального наложенного загрязнения ртутью природных сред обусловлен в основном ее прошлой добычей и применением. Концентрации ртути в загрязненных природных средах тесно связаны между собой. Основными источниками антропогенной эмиссии ртути являются лежалые отходы горнодобывающих предприятий. Современная хозяйственная деятельность в регионе не создает опасного загрязнения природной среды.
\end{abstract}

\section{Ключевые слова:}

Республика Алтай, ртуть, природные среды, источники выбросов, уровни содержания, наложенное загрязнение, локальный и региональный фон.

\section{Введение}

Известно, что основные факторы эмиссии ртути в окружающую среду - природный и антропогенный, первый из которых определяется спецификой геологической среды, а второй - хозяйственной деятельностью человека $[1,2]$. На территории Республики Алтай (РА) проявлены обе группы источников повышенного и реже аномально высокого поступления ртути в природную среду [3]. Первая из них представлена рядом месторождений и проявлений ртути, сопровождающихся лито- и биогеохимическими ореолами ее рассеяния. Ртуть в повышенных концентрациях присутствует также в качестве элементаспутника в рудах многих месторождений цветных и благородных металлов [4].

Вторая группа источников, характеризующаяся прямым или косвенным характером вовлечения ртути в миграционные процессы, представлена двумя подгруппами - природно-антропогенной и собственно антропогенной [5]. К природно-антропогенной подгруппе относятся природные источники ртути, «активизированные» в процессе геологоразведочных работ, добычи, обогащения и передела ртутных и ртутьсодержащих руд, а также загрязненные при этом ртутью природные среды (источники вторичного загрязнения).

Подгруппа антропогенных источников обусловлена использованием ртути и содержащих ее материалов и изделий в хозяйственной деятельности, главным образом при добыче россыпного (шлихового) золота, а также при не отвечающем требованиям экологической безопасности хранении отходов горнодобывающих предприятий (ГДП) и других ртутьсодержащих отходов (РСО) производства и потребления.

Масштабы и экологические последствия природной и антропогенной эмиссии ртути на территории РА в настоящее время изучены недостаточно. Тем не менее проведенными в последние четверть века ря- 
дом научных и производственных организаций разноплановыми региональными и локальными экологогеохимическими исследованиями получен большой объем данных по уровням содержания ртути в объектах геологической среды и в компонентах природной среды, а также в производственных отходах $[3,6,7]$.

Основным импульсом для изучения распределения ртути в объектах окружающей среды РА явилось запланированное строительство каскада ГЭС в среднем течении р. Катунь. В 1988-1990 гг. рядом институтов СО АН СССР были проведены разноплановые исследования особенностей распределения ртути в районе проектируемого Катунского гидроузла. Этими работами установлен локальный слабо концентрированный характер распределения ртути и ее подвижных форм в природных средах и геологических образованиях изученной территории [8-10].

Систематизация и анализ этой информации и данных последующих работ явились целью обобщения, краткие результаты которого приведены в настоящей статье. Основные его задачи заключались в изучении уровней содержания ртути в вышеотмеченных объектах, в предварительной оценке ее регионального фона в природных средах РА и его сравнении с кларками и фоновыми значениями на территории других регионов Сибири.

Другая цель проведенного обобщения заключается в проверке вывода о высокой экологической опасности тяжелометального, в том числе ртутного загрязнения природной среды на территории РА [11], который в определенной степени лимитирует развитие туристско-рекреационной отрасли, одной из ведущих в республике.

\section{Информационные материалы}

Фактической основой настоящего обобщения явились в основном материалы проведенных в 1990-х гг. эколого-геохимических работ масштаба 1:1000000 (Алтайский полигон МГХК-1000, 1994; ГЭИК-1000 в Алтайском крае и Республике Алтай, 1996; Геохимическая основа Госгеолкарты листа М-45, 2001), а также данные локальных геоэкологических обследований на территории РА в 1992-2020 гг. Исполнителями этих работ были производственные (АО «АлтайГео», АО «Горно-Алтайская экспедиция», ФГУГП «Запсибгеолсъемка») и научные организации, в том числе ИМГРЭ, ИГиМ СО РАН, ИВЭП СО РАН, АРИ «Экология» и др.

Основная часть фактического материала по содержанию и распределению ртути в изученных средах содержится в фондовых отчетах этих организаций В немногих публикациях по теме приведены в основном уровни содержания ртути в природных средах изученных территорий.

В рамках вышеотмеченных исследований на территории РА было проанализировано на ртуть около двух тысяч проб горных пород, почв, природных вод, образцов растений, а также проведено более полутора тысяч измерений концентраций ртути в атмосферном и почвенном воздухе газортутным анализатором АГП-01.
Анализы всех проб на ртуть проведены методом атомной абсорбции («холодного пара») в следующих аккредитованных лабораториях: Западно-Сибирском испытательном центре (г. Новокузнецк); лабораториях ИГиМ СО РАН (г. Новосибирск), ИМГРЭ (г. Москва), ИВЭП СО РАН (г. Барнаул), НИ ТПУ (г. Томск). Пределы обнаружения ртути для использованных методик составили для почв, донных отложений и растений -5 мкг/кг, для воды -2 мкг/дм³ ${ }^{3}$ Достоверность полученных в этих лабораториях данных обеспечена репрезентативными объемами и удовлетворительной сходимостью результатов межлабораторного (5-10 \% от всего объема проб) и внутреннего контроля (3-7\%).

Обработка и интерпретация полученных результатов заключалась в их систематизации, создании базы данных в формате dBase, в формировании и последующей статистической обработке с помощью программ «Statistika 6.1» и «Microsoft Excel 2000» peпрезентативных выборок по геологическим формациям, структурно-формационным зонам, физикогеографическим районам, основным типам ландшафтов, природным средам, населенным пунктам, источникам техногенного загрязнения и пр.

\section{Результаты и их обсуждение}

Природные источники эмиссии ртути на территории Республики Алтай. Для Горного Алтая характерно эпитермальное ртутное оруденение, связываемое с раннемезозойской (юрской) тектономагматической активизацией региона $[4,12]$. На его территории выявлен ряд месторождений и проявлений ртути карбонатнокиноварного и магнезиально-карбонатно-киноварного (лиственнитового), реже кварц-флюорит-киноварного и кварц-диккит-киноварного типов, а также многочисленные литохимические и шлиховые ореолы ее рассеяния, приуроченные к протяженным (сотни км) зонам глубинных разломов и сопряженных с ними разрывных нарушений (рис. 1). Ртуть также присутствует как элемент-спутник в рудах месторождений цветных, редких и благородных металлов.

Максимальный уровень природных концентраций ртути проявлен в ее рудах $-\mathrm{n} \times 0,1 \ldots 1,0 \%$. В других металлических и нерудных полезных ископаемых он на 3-4 порядка ниже. Так, содержание ртути в рудах Синюхинского и Калгутинского месторождений не превышает 0,1 и 0,3 мг/кг соответственно, а в каменных углях Курайского месторождения находится на уровне фона почв. Содержание ртути во вторичных ореолах рассеяния рудных месторождений составляет в основном сотые-десятые доли мг/кг, а на участках ртутнорудных объектов - до первых мг/кг (табл. 1).

Природно-техногенные факторы эмиссии ртути представлены участками разведки месторождений, промышленными зонами ГДП, а также загрязненными их выбросами, сбросами и отходами объектами окружающей среды (почвы, грунты, донные отложения). Так, концентрации ртути в выбросах металлозавода бывшего Акташского рудника, а впоследствии одноименного горно-металлургического предприятия

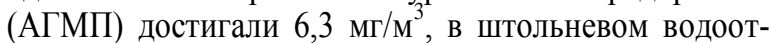


ливе 0,6 мкг/дм ${ }^{3}$, в металлургических шлаках (огарках) до 1 кг/т, в шламах до 150 кг/т $[13,14]$.

Повышенный уровень содержания ртути (до 10 мг/кг) отмечен в отходах обогащения руд ряда ме- сторождений цветных, редких и благородных металлов (табл. 1), а также в выбросах предприятий цветной металлургии Восточного Казахстана, переносимых на территорию Алтая [14].

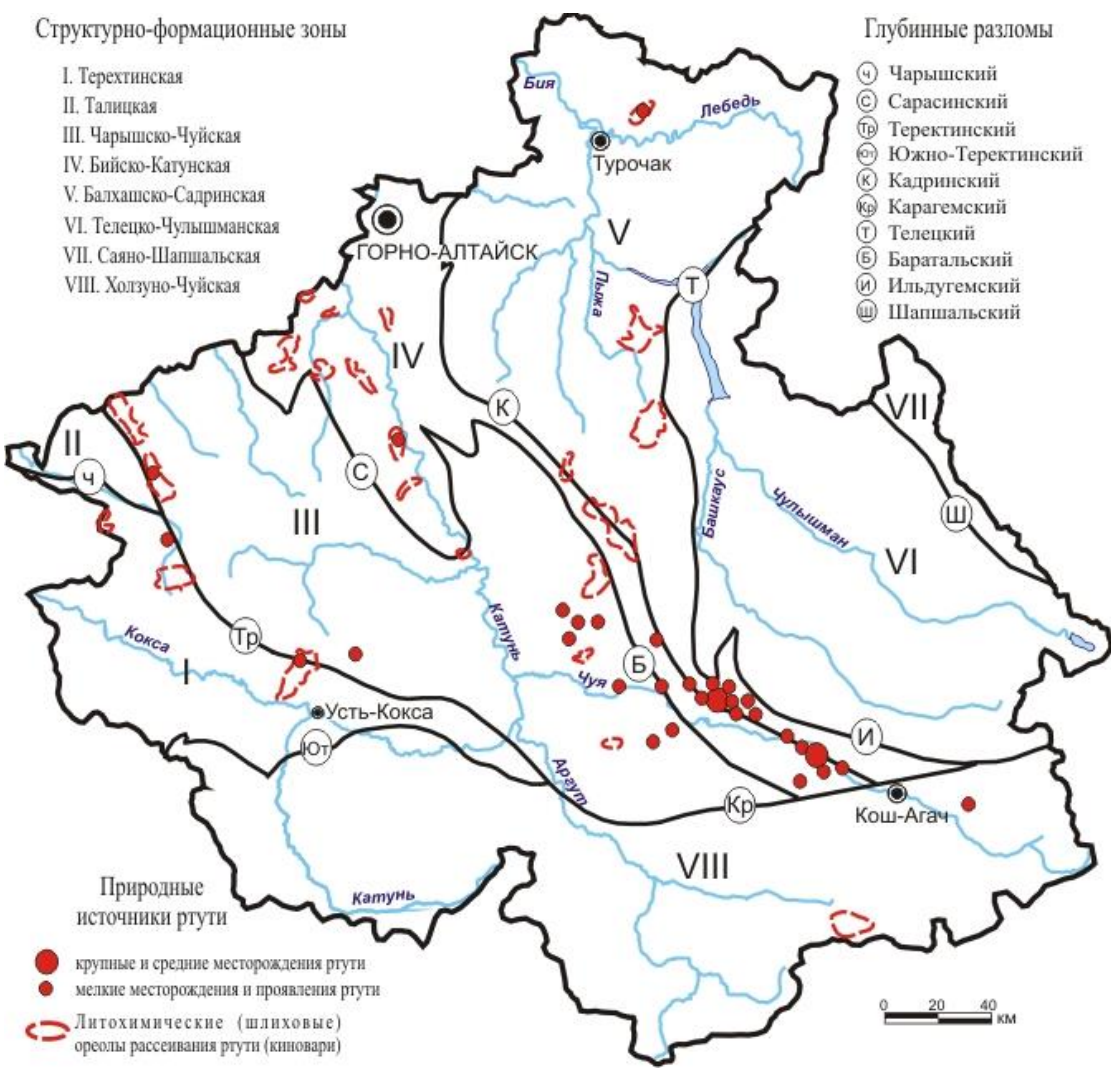

Рис. 1. Геолого-структурная позиция проявлений ртути в Республике Алтай

Fig. 1. Geological and structural position of mercury manifestations in the Altai Republic

Таблица 1. Содержание ртути в источниках ее эмиссии в природную среду РА

Table 1. Mercury content in the sources of its emission into the natural environment of the Altai Republic

\begin{tabular}{|c|c|c|c|c|c|c|c|c|}
\hline \multicolumn{9}{|c|}{ Содержание ртути в ее природных источниках/Mercury content in its natural sources } \\
\hline \multirow[b]{2}{*}{$\begin{array}{l}\text { Параметры } \\
\text { Parameters }\end{array}$} & \multicolumn{6}{|c|}{$\begin{array}{c}\text { Месторождения ртути и других полезных ископаемых } \\
\text { Deposits of mercury and other minerals }\end{array}$} & \multicolumn{2}{|c|}{$\begin{array}{l}\text { Вторичные ореолы } \mathrm{Hg} \\
\text { Secondary auras of } \mathrm{Hg}\end{array}$} \\
\hline & $\begin{array}{c}\text { Акташское } \\
\text { Aktash } \\
(\mathrm{Hg})\end{array}$ & \multicolumn{2}{|c|}{$\begin{array}{c}\text { Чаган-Узун } \\
\text { Chagan-Uzun } \\
(\mathrm{Hg})\end{array}$} & $\begin{array}{c}\text { Калгуты } \\
\text { Kalgut } \\
\text { (W, Mo) }\end{array}$ & $\begin{array}{l}\text { Синюхинское } \\
\text { Sinyukha } \\
(\mathrm{Au})\end{array}$ & $\begin{array}{l}\text { Курайское } \\
\text { (уголь) } \\
\text { Kurai (coal) }\end{array}$ & $\begin{array}{c}\text { Акташское } \\
\text { Aktash } \\
(\mathrm{Hg})\end{array}$ & $\begin{array}{l}\text { Синюхинское } \\
\text { Sinyukha } \\
(\mathrm{Au})\end{array}$ \\
\hline $\lim$, мкг/кг (mcg/kg) & $0,1 \ldots 10,8 \times 10^{7}$ & \multicolumn{2}{|c|}{$0,1 \ldots 1,5 \times 10^{7}$} & $50-300$ & $5-100$ & $1-80$ & $100-500$ & $10-300$ \\
\hline $\bar{x}$, Мкг/Кг $(\mathrm{mcg} / \mathrm{kg})$ & $1,25 \times 10^{7}$ & \multicolumn{2}{|c|}{$0,47 \times 10^{7}$} & 200 & 30 & 50 & $100-300$ & 100 \\
\hline \multicolumn{9}{|c|}{$\begin{array}{l}\text { Содержание ртути в твердых природно-техногенных источниках вторичного загрязнения } \\
\text { Mercury content in solid natural and man-made sources of secondary pollution }\end{array}$} \\
\hline \multirow{2}{*}{$\begin{array}{l}\text { Параметры } \\
\text { Parameters }\end{array}$} & \multicolumn{3}{|c|}{$\begin{array}{l}\text { Производственные отходы, г/т } \\
\text { Production waste, g/t }\end{array}$} & \multicolumn{3}{|c|}{$\begin{array}{c}\text { Почвы промзон рудников } \\
\text { Soils of industrial zones of mines }\end{array}$} & \multicolumn{2}{|c|}{$\begin{array}{c}\text { Донные осадки рек } \\
\text { Bottom sediments of rivers }\end{array}$} \\
\hline & \begin{tabular}{l|l} 
Шлаки $^{1}$ \\
Slags $^{1}$
\end{tabular} & \begin{tabular}{l|} 
Хвосты $^{2}$ \\
Tails $^{2}$
\end{tabular} & $\begin{array}{c}\text { Хвосты }^{3} \\
\text { Tails }^{3}\end{array}$ & $\begin{array}{l}\text { АГМП } \\
\text { AGME }\end{array}$ & $\begin{array}{c}\text { «Калгуты» } \\
\text { «Kalgut» }\end{array}$ & $\begin{array}{l}\text { «Веселый» } \\
\text { «Vesely» }\end{array}$ & $\begin{array}{l}\text { Ярлыамры } \\
\text { Yarlyamry }\end{array}$ & $\begin{array}{l}\text { Синюха } \\
\text { Sinyukha }\end{array}$ \\
\hline $\lim$, мкг/кг (mcg/kg) & $161-1000$ & $1,0-6,3$ & $1-10$ & $1-1000$ & $0,04-30$ & $0,1-6,3$ & $10-103$ & $0,2-2,1$ \\
\hline $\bar{x}$, мкг/кг (mcg/kg) & 250 & 2,6 & 5,0 & 29,0 & 8,9 & 1,0 & 37,3 & 1,1 \\
\hline \multicolumn{9}{|c|}{$\begin{array}{c}\text { Содержание ртути в жидких природно-техногенных источниках вторичного загрязнения } \\
\text { Mercury content in liquid natural and man-made sources of secondary pollution }\end{array}$} \\
\hline \multirow{2}{*}{$\begin{array}{l}\text { Параметры } \\
\text { Parameters }\end{array}$} & \multicolumn{3}{|c|}{$\begin{array}{c}\text { Водоотлив рудников } \\
\text { Mine drainage }\end{array}$} & \multicolumn{3}{|c|}{$\begin{array}{l}\text { Технологические воды рудников } \\
\text { Process waters drainage }\end{array}$} & \multicolumn{2}{|c|}{$\begin{array}{l}\text { Вода загрязненных рек } \\
\text { Water of polluted rivers }\end{array}$} \\
\hline & $\begin{array}{l}\mathrm{A} \Gamma \mathrm{M} \\
\mathrm{AGME}\end{array}$ & \begin{tabular}{c|} 
«Майский» \\
«Maysky»
\end{tabular} & $\begin{array}{c}\text { «веселый» } \\
\text { «Vesely» }\end{array}$ & $\begin{array}{l}\text { АГМП } \\
\text { AGME }\end{array}$ & $\begin{array}{l}\text { «Майский» } \\
\text { «Maysky» }\end{array}$ & $\begin{array}{l}\text { «Веселый» } \\
\text { «Vesely» }\end{array}$ & \begin{tabular}{c|} 
Ярлыамры \\
Yarlyamry
\end{tabular} & $\begin{array}{c}\text { Синюха } \\
\text { Sinyukha }\end{array}$ \\
\hline $\lim$, мкг/л (mcg/l) & $0,2-0,6$ & $0,11-0,34$ & $0,07-0,17$ & до 13900 & $0,07-180$ & $0,10-9,3$ & $0,07-2,4$ & $0,06-0,46$ \\
\hline $\bar{x}$ мкг/л (mcg/l) & 0,32 & 0.20 & 0.10 & 2500 & 0.45 & 0.20 & 0,30 & 0.12 \\
\hline
\end{tabular}

lim - минимальное...ммаксимальное содержание, $x$ - среднее содержание, $N$ - число проб. Производственные отходы: 1 - АГМП, 2 - рудник «Весельй », 3 - рудник «Калгутьъ».

lim - minimum...maximum content, $x$ - average content, $N$ - number of samples. Production waste: $1-A G M E, 2-« V e s e l y »$ mine, $3-«$ Kalguty» mine. 
Содержание ртути в загрязненных почвах варьируется в широких пределах - от единиц-десятков мкг/кг до первых тысяч - сотен тысяч мкг/кг в промзонах рудников, а также горнодобывающих предприятий, использовавших ртуть для извлечения золота. Такой же уровень концентраций ртути отмечен в донных отложениях рек, загрязненных твердыми отходами ГДП.

Повышенный уровень содержания ртути проявлен в жидких природно-техногенных источниках вторичного загрязнения - в водоотливе разведочноэксплуатационных горных выработок, в технологических водах горнодобывающих предприятий, а также в загрязненных их сбросами поверхностных водных объектах. В технологических водах ГДП, размещаемых, как правило, в технически необорудованных прудках-отстойниках, проявлены повышенные и аномально высокие концентрации ртути - до первых десятков и реже тысяч мкг/дм ${ }^{3}$. В других источниках вторичного загрязнения ее содержание составляет в основном десятки мкг/дм ${ }^{3}$ (табл. 1).
Техногенные источники эмиссии ртути в окружающую среду представлены в основном привозными ртутьсодержащими отходами промышленных предприятий Сибирского региона, хвостами золотоизвлекательной фабрики рудника «Веселый», а также участками прошлого использования ртути при отработке золотоносных россыпей в северной части региона (бассейны рек Бия, Лебедь, Саракокша), приводящей к загрязнению всего комплекса природных сред [5].

Второстепенными источниками антропогенного поступления ртути в окружающую среду являются селитебные зоны (сжигание угля, размещение отходов и др.) и пахотные земли под зерновыми культурами, семена которых обрабатывались ртутьсодержащим фунгицидами (гранозан и др.) [15-17]. С учетом небольшой численности и рассредоточенности населения, преобладания аграрного производства, а также низкой доли пашни (1,3\% от площади РА) уровень эмиссии ртути от этих источников представляется незначительным (рис. 2).

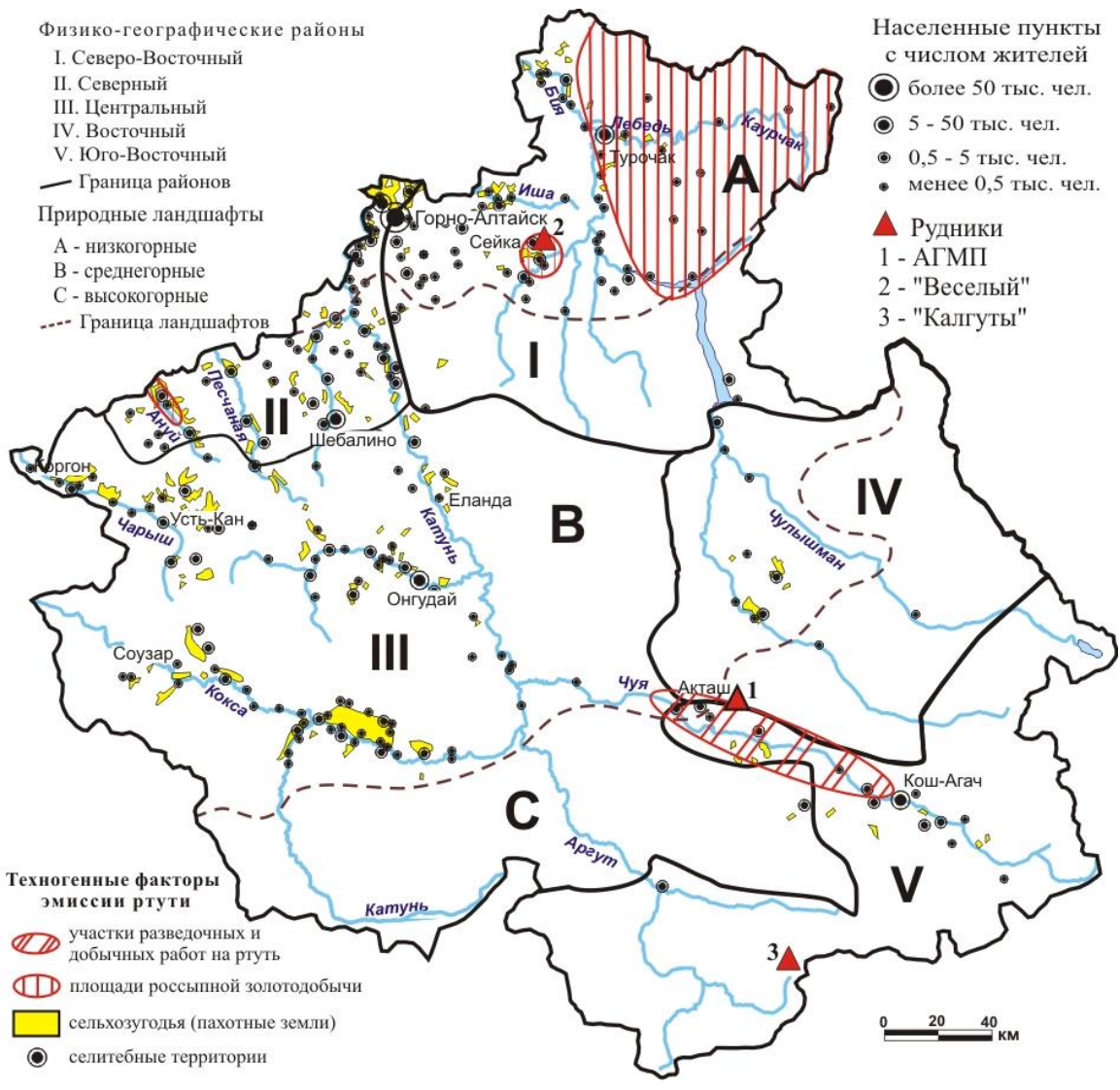

Pис. 2. Потенциальные источники эмиссии ртути в окружающую среду РА

Fig. 2. Potential sources of mercury emissions into the RA environment

Уровни содержания ртути в природных средах. Ртуть в фоновых, реже в повышенных и высоких концентрациях присутствует во всех компонентах природной среды региона - от горных пород до атмосферного воздуха, в котором повышенное содержание ртути, особенно в почвенном воздухе, служит надежным индикатором ее повышенного присутствия в почвообразующих породах.
По данным МГХК-1000 [6], среднее содержание ртути в породах геологических формаций Горного Алтая варьируется в пределах 30-440 мкг/кг и в среднем составляет 100 мкг/кг. Этот региональный фон находится на уровне кларка литосферы и предопределяет концентрации ртути в приземной атмосфере населенных пунктов Республики Алтай на уровне

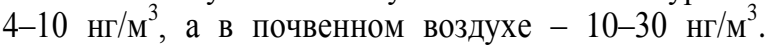


В населенных пунктах региона, где находятся объекты инфраструктуры ГДП, добывающих или применяющих ртуть, ее концентрации в приземной атмосфере выше на порядок, а в почвенном воздухе выше на два порядка. При этом содержания ртути в почвенном и атмосферном воздухе тесно связаны между собой (табл. 2).
Основными источниками эмиссии ртути в атмосферу региона являются производственные отходы ГДП и загрязненные ими почвы [13]. Так, концентрации ртути в приземной атмосфере над терриконами огарков АГМП и захоронениями привозных РСО достигает 7 мкг $/ \mathrm{M}^{3}$ (23 ПДК), а в почвенном воздухе на территории промзоны -60 мкг $/ \mathrm{M}^{3}$.

Таблица 2. Содержание ртути в атмосферном и почвенном воздухе

Table 2. Mercury content in atmospheric and soil air

\begin{tabular}{|c|c|c|c|c|c|c|c|c|}
\hline \multicolumn{9}{|c|}{$\begin{array}{c}\text { Содержание ртути в воздухе населенных пунктов Республики Алтай и Алтайского края } \\
\text { Mercury content in the air of settlements of the Altai Republic and the Altai territory }\end{array}$} \\
\hline $\begin{array}{l}\text { Параметры } \\
\text { Parameters }\end{array}$ & $\begin{array}{l}\text { AkтaiI } \\
\text { Aktash }\end{array}$ & $\begin{array}{l}\text { Сейка } \\
\text { Seyka }\end{array}$ & $\begin{array}{l}\text { Улаган } \\
\text { Ulagan }\end{array}$ & $\begin{array}{l}\text { Чемал } \\
\text { Chemal }\end{array}$ & $\begin{array}{l}\text { Шебалино } \\
\text { Shebalino }\end{array}$ & $\begin{array}{c}\text { Горно-Алтайск } \\
\text { Gorno-Altaisk }\end{array}$ & $\begin{array}{l}\text { Барнаул } \\
\text { Barnaul }\end{array}$ & $\begin{array}{l}\text { Бийск } \\
\text { Biysk }\end{array}$ \\
\hline$N$, ед. (un.) & 32 & 175 & 28 & 28 & 18 & 51 & 103 & 69 \\
\hline $\lim , \mathrm{H \Gamma} / \mathrm{M}^{3}\left(\mathrm{ng} / \mathrm{m}^{3}\right)$ & $<2-200$ & $<2-264$ & $<2-24$ & $<2-12$ & $<2-36$ & $<2-8$ & $<2-59$ & $<2-13$ \\
\hline $\bar{x}, \mathrm{H} \Gamma / \mathrm{m}^{3}\left(\mathrm{ng} / \mathrm{m}^{3}\right)$ & 38,7 & 68,4 & 7,0 & 5,3 & 8,6 & 4,0 & 5,0 & 8,0 \\
\hline \multicolumn{9}{|c|}{$\begin{array}{c}\text { Содержание ртути в почвенном воздухе населенных пунктов Республики Алтай } \\
\text { Mercury content in the soil air of settlements of the Altai Republic }\end{array}$} \\
\hline $\begin{array}{l}\text { Параметры } \\
\text { Parameters }\end{array}$ & $\begin{array}{l}\text { AkтaII } \\
\text { Aktash }\end{array}$ & $\begin{array}{l}\text { Сейка } \\
\text { Seyka }\end{array}$ & $\begin{array}{l}\text { Майское } \\
\text { Maiskoe }\end{array}$ & $\begin{array}{l}\text { Tалон } \\
\text { Talon }\end{array}$ & $\begin{array}{l}\text { Чибит } \\
\text { Chibit }\end{array}$ & $\begin{array}{l}\text { Улаган } \\
\text { Ulagan }\end{array}$ & $\begin{array}{l}\text { Чемал } \\
\text { Chemal }\end{array}$ & $\begin{array}{l}\text { Шебалино } \\
\text { Shebalino }\end{array}$ \\
\hline$N$, ед. (un.) & 32 & 175 & 30 & 18 & 11 & 28 & 28 & 18 \\
\hline $\lim , \mathrm{H \Gamma} / \mathrm{m}^{3}\left(\mathrm{ng} / \mathrm{m}^{3}\right)$ & $45-5188$ & $<2-4936$ & $36-5243$ & $44-660$ & $4-82$ & $<2-38$ & $4-50$ & $<2-52$ \\
\hline $\bar{x}, \mathrm{H} \Gamma / \mathrm{M}^{3}\left(\mathrm{ng} / \mathrm{m}^{3}\right)$ & 787 & 165 & 204 & 312 & 27,3 & 13,3 & 19,1 & 14,3 \\
\hline $\mathrm{R}^{*}$ & 0,68 & 0,38 & \multicolumn{2}{|c|}{ нет данных/no data } & 0,79 & 0,59 & 0,52 & 0,60 \\
\hline
\end{tabular}

* - значения парной корреляции в почвенном и атмосферном воздухе при $p=0,01$; выделены населенные пункты с загрязненным ртутью почвенным покровом. Остальные условные обозначения в табл. 1.

* - values of the pair correlation in soil and atmospheric air at p=0,01; settlements with mercury-contaminated soil cover are identified. The remaining symbols are shown in Table 1.

Содержание ртути в незагрязненных почвах региона варьируется в относительно узких пределах 10-270 мкг/кг при среднем 110 мкг/кг, которое можно считать региональным фоном. Среднее содержание ртути для разных типов почв изменяется от 77 мкг/кг для горнолесных дерново-подзолистых почв до 170 мкг/кг для черноземов южных. Повышенные ее концентрации (130-160 мкг/кг) характерны также для каштановых почв Чуйской и Курайской межгорных котловин Юго-Восточного Алтая [7].

Характерной особенностью поведения ртути в почвах является увеличение ее содержания в ряду «низкогорныесреднегорные-высокогорные ландшафты», объясняемое более легким механическим составом и повышенной степенью выветривания почвообразующих пород в условиях высокогорья. Идентичный, но менее выраженный тренд увеличения содержания ртути в почвах проявлен в ряду физико-географических районов: Северо-ВосточныйЦентральный-Юго-Восточный Алтай (табл. 3).

Другая особенность поведения ртути в почвах заключается в ее накоплении в верхней части гумусового горизонта А в среднем в полтора раза выше относительно нижних горизонтов (BC, С), объясняемое более активным образованием ртутьорганических соединений [18]. Это отношение сохраняется для всех типов природных ландшафтов Горного Алтая.

Таблица 3. Содержание ртути в почвах РА (по материалам ГЭИК-1000)

Table 3. Mercury content in RA soils (based on GERM-1000 materials)

\begin{tabular}{|c|c|c|c|c|c|}
\hline \multicolumn{6}{|c|}{$\begin{array}{l}\text { Содержание ртути в почвенном горизонте А основных типов ландшафтов } \\
\text { Mercury content in the soil horizon A of the main types of landscapes }\end{array}$} \\
\hline $\begin{array}{l}\text { Параметры } \\
\text { Parameters }\end{array}$ & $\begin{array}{l}\text { низкогорные } \\
\text { low mountains }\end{array}$ & $\begin{array}{l}\text { среднегорные } \\
\text { mid-mountain }\end{array}$ & $\begin{array}{l}\text { высокогорные } \\
\text { high mountains }\end{array}$ & $\begin{array}{l}\text { межгорные впадины } \\
\text { intermountain hollows }\end{array}$ & $\begin{array}{l}\text { среднее } \\
\text { average }\end{array}$ \\
\hline$N$, ед. (un.) & 30 & 24 & 22 & 13 & 89 \\
\hline $\lim$, мкг/кг (mcg/l) & $10-143$ & $60-150$ & $95-270$ & $75-270$ & $10-270$ \\
\hline$\overline{\bar{x}}$, мкг/кг (mcg/l) & 68 & 125 & 190 & 169 & 115 \\
\hline \multicolumn{6}{|c|}{$\begin{array}{c}\text { Содержание ртути в почвенных горизонтах ВC, С основных типов ландшафтов } \\
\text { Mercury content in soil horizons BC, C the main types of landscapes }\end{array}$} \\
\hline$N$, ед. (un.) & 29 & 13 & 10 & 8 & 60 \\
\hline $\lim$, мкг/кг (mcg/l) & $10-150$ & $10-150$ & $20-200$ & $50-150$ & $10-200$ \\
\hline$\overline{\bar{x}}$, мкг/кг (mcg/l) & 45 & 80 & 120 & 110 & 75 \\
\hline A/BC, С ед. (C un.) & 1,51 & 1,56 & 1,58 & 1,54 & 1,53 \\
\hline
\end{tabular}

Среднее содержание ртути во всех типах растительности региона также варьируется в узких пределах - 12-20 мкг/кг, но для отдельных семейств и видов растений имеются двухи трехкратные различия. В зонах влияния ГДП ее содержание в разнотравье в 5-50 раз выше, чем на фоновой террито- рии РА и других регионов [19-21]. Максимальные концентрации ртути отмечены в разнотравье промзоны бывшего АГМП - до 35000 мкг/кг, или 700 МДУ, в зонах влияния других ГДП ее содержание в травянистых растениях не превышает десятых долей мг/кг (табл. 4). 
Таблица 4. Содержание ртути в растительности на территории РА

Table 4. Mercury content in vegetation on the territory of the Altai Republic

\begin{tabular}{|l|c|c|c|c|c|c|c|c|c|}
\hline \multirow{2}{*}{$\begin{array}{c}\text { Параметры } \\
\text { Parameters }\end{array}$} & \multicolumn{2}{|c|}{$\begin{array}{c}\text { Древесные виды } \\
\text { Wood species }\end{array}$} & \multicolumn{2}{c|}{$\begin{array}{c}\text { Травянистые виды (разнотравье) } \\
\text { Herbaceous species (herbs) }\end{array}$} & \multicolumn{3}{c|}{$\begin{array}{c}\text { Разнотравье в зонах рудников } \\
\text { Mixed grasses in mine zones }\end{array}$} \\
\cline { 2 - 11 } & $\begin{array}{c}\text { Хвойные } \\
\text { Conifer }\end{array}$ & $\begin{array}{c}\text { Лиственные } \\
\text { Foliate }\end{array}$ & I & II & III & IV & $\begin{array}{c}\text { AГMП } \\
\text { AGME }\end{array}$ & $\begin{array}{c}\text { «Калгуты» } \\
\text { «Kalguty» }\end{array}$ & $\begin{array}{c}\text { «Beceлый» } \\
\text { «Vesely» }\end{array}$ \\
\hline$N$, ед. (un.) & 16 & 28 & 52 & 16 & 34 & 54 & 74 & 10 & 19 \\
\hline $\lim$, мкг/кг $(\mathrm{mcg} / \mathrm{l})$ & $8-28$ & $10-32$ & $6-70$ & $7-15$ & $5-59$ & $3-64$ & $40-35000$ & $80-480$ & $50-160$ \\
\hline $\bar{x}$, мкг/кг $(\mathrm{mcg} / \mathrm{l})$ & 18,5 & 20,0 & 17,3 & 11,8 & 19,7 & 15,8 & 860 & 220 & 97 \\
\hline
\end{tabular}

$I$ - бассейн р. Катунь, II - район оз. Телеияке, III-плато Укок; IV-межгорные котловины.

I-Katun river basin, II - Teletskoe lake district, III - Ukok plateau; IV-intermountain basins.

Картина распределения ртути в поверхностных водах региона идентична той, что отмечена для растений. Так, ее максимальное содержание в воде рек 2-3 порядка (относительно р. Обь) составляет $0,30 \ldots 0,43$ мкг/дм ${ }^{3}$ при среднем $0,1 \ldots 0,15$ мкг/дм ${ }^{3}$ (табл. 5). Это свидетельствует о близких концентрациях ртути в геологических образованиях водосборных бассейнов рек, а также о близости природных условий перехода ртути в водную среду.
В донных отложениях рек среднее содержание ртути варьируется от 80 до 350 мкг/кг, при этом максимальные концентрации проявлены главным образом в мелкопесчано-глинисто-илистых фракциях наносов рек северной и северо-восточной низкогорных частей РА (Лебедь, Бия, Иша, Каурчак и др.). Для этих рек нередко присущи значимые обратные связи содержания ртути в воде и донных отложениях.

Таблица 5. Среднее содержание ртути в речных водах и донных отложениях $P A$

Table 5. Average mercury content in river waters and bottom sediments of the RA

\begin{tabular}{|c|c|c|c|c|c|c|c|c|}
\hline \multirow{2}{*}{$\begin{array}{l}\text { Параметры } \\
\text { Parameters }\end{array}$} & \multicolumn{8}{|c|}{ Вода рек 2-3 порядков/Water of rivers of $2-3$ orders } \\
\hline & $\begin{array}{l}\text { Катунь } \\
\text { Katun }\end{array}$ & $\begin{array}{l}\text { Чарыш } \\
\text { Charysh }\end{array}$ & \multicolumn{2}{|c|}{$\begin{array}{l}\text { Ануй } \\
\text { Anui }\end{array}$} & $\begin{array}{c}\text { Песчаная } \\
\text { Peschanaya }\end{array}$ & $\begin{array}{c}\text { Лебедь } \\
\text { Lebed }\end{array}$ & $\begin{array}{l}\text { Чулышман } \\
\text { Chulyshman }\end{array}$ & $\begin{array}{l}\text { Каурчак } \\
\text { Kaurchak }\end{array}$ \\
\hline$N$, ед. (un.) & 20 & 58 & \multicolumn{2}{|c|}{18} & 12 & 4 & 5 & 17 \\
\hline $\lim$, мкг/л (mcg/l) & $0,02-0,30$ & $0,01-0,43$ & \multicolumn{2}{|c|}{$0,01-0,30$} & $0,01-0,36$ & $0,01-0,17$ & $0,01-0,05$ & $0,01-0,37$ \\
\hline $\bar{x}$, мкг/л $(\mathrm{mcg} / \mathrm{l})$ & 0,16 & 0,13 & 0 , & & 0,11 & 0,13 & 0,03 & 0,16 \\
\hline \multicolumn{9}{|c|}{ Донные отложения рек/Bottom sediments of rivers } \\
\hline $\begin{array}{l}\text { Параметры } \\
\text { Parameters }\end{array}$ & $\begin{array}{l}\text { Катунь } \\
\text { Katun }\end{array}$ & $\begin{array}{l}\text { Бия } \\
\text { Biya }\end{array}$ & $\begin{array}{l}\text { Чарыш } \\
\text { Charysh }\end{array}$ & $\begin{array}{c}\text { Aргут } \\
\text { Argut }\end{array}$ & $\begin{array}{c}\text { Песчаная } \\
\text { Peschanaya }\end{array}$ & $\begin{array}{c}\text { Лебедь } \\
\text { Lebed }\end{array}$ & $\begin{array}{l}\text { Кокса } \\
\text { Koksa }\end{array}$ & $\begin{array}{l}\text { Иша } \\
\text { Isha }\end{array}$ \\
\hline$N$, ед. (un.) & 17 & 10 & 29 & 5 & 6 & 5 & 11 & 10 \\
\hline $\lim$, мкг/кг $(\mathrm{mcg} / \mathrm{l})$ & $50-350$ & $150-320$ & $10-300$ & $20-300$ & $60-300$ & $150-300$ & $80-300$ & $170-340$ \\
\hline $\bar{x}$, мкг/кГ (mcg/l) & 219 & 237 & 98 & 120 & 184 & 244 & 162 & 255 \\
\hline
\end{tabular}

В основных типах подземных вод складчатого палеозойского фундамента (жильные, трещинные, карстовые) и рыхлого покровного чехла (грунтовые воды) содержание ртути в целом в 2-3 раза ниже, чем в по- верхностных водах. Так, ее среднее содержание в питьевых подземных водах находится на уровне $0,02 \ldots 0,08$ мкг/дм ${ }^{3}$ при преобладании значений $0,04 \ldots 0,06$ мкг/дм ${ }^{3}$ (табл. 6).

Таблица 6. Среднее содержание ртути в подземных водах населенных пунктов РА

Table 6. Average mercury content in underground waters of Altai Republic settlements

\begin{tabular}{|c|c|c|c|c|c|c|c|}
\hline \multicolumn{7}{|c|}{ Содержание ртути в грунтовых водах отложений рыхлого чехла в населенных пунктах } \\
Mercury content in ground water of loose cover deposits in populated areas \\
\hline $\begin{array}{c}\text { Параметры } \\
\text { Parameters }\end{array}$ & $\begin{array}{c}\text { Г-Алтайск } \\
\text { G-Altaisk }\end{array}$ & $\begin{array}{c}\text { Шебалино } \\
\text { Shebalino }\end{array}$ & $\begin{array}{c}\text { Ceйка } \\
\text { Seyka }\end{array}$ & $\begin{array}{c}\text { Tyрочак } \\
\text { Turochak }\end{array}$ & $\begin{array}{c}\text { Kopгон } \\
\text { Korgon }\end{array}$ & $\begin{array}{c}\text { Apтыбаш } \\
\text { Artybash }\end{array}$ & $\begin{array}{c}\text { Aкташ } \\
\text { Aktash }\end{array}$ \\
\hline$N$, ед. (un.) & 26 & 13 & 38 & 9 & 15 & 10 & 9 \\
\hline max, мкг/л (mcg/l) & 0,31 & 0,22 & 0,27 & 0,35 & 0,25 & 0,13 & 0,09 \\
\hline $\bar{x}$, мкг/л (mcg/l) & 0,05 & 0,06 & 0,04 & 0,07 & 0,05 & 0,02 & 0,04 \\
\hline \multicolumn{7}{|c|}{ Содержание ртути в подземных водах складчатого фундамента } \\
Mercury content in underground waters of the folded Foundation \\
\hline Параметры \\
Parameters
\end{tabular}

Анализ корреляционных связей ртути в сопряженных пробах природных сред в условно фоновых и слабо загрязненных населенных пунктах региона (Акташ, Сейка) показал наличие прямой зависимости ее содержания в приземном воздухе (на высоте 1,5 м), почвенном воздухе, почвах и почвообразующих породах складчатого фундамента (табл. 7). Исключением является незначимый уровень связи между содержанием ртути в приземном воздухе и коренных породах, что объясняется превалирующим отсутствием их непосредственного контакта. 
Таблица 7. Связи ртути в сопряженных природных средах населенных пунктов

Table 7. Mercury bonds in conjugated natural environments of human settlements

\begin{tabular}{|c|c|c|c|c|c|c|c|c|c|c|c|c|}
\hline \multirow{2}{*}{$\begin{array}{c}\text { Природные среды } \\
\text { Natural environments }\end{array}$} & \multicolumn{4}{|c|}{ Акташ/Aktash $(\mathrm{n}=32)$} & \multicolumn{4}{|c|}{ Чибит/Chibit, Иня/Inya (n=22) } & \multicolumn{4}{|c|}{ Еланда/Elanda $(\mathrm{n}=126)$} \\
\hline & $\mathrm{I}$ & II & III & IV & $\mathrm{I}$ & II & III & IV & I & II & III & IV \\
\hline I. Атмосферный воздух/Atmospheric air & 1 & 0,68 & 0,36 & 0,05 & 1 & $\mathbf{0 , 7 9}$ & $\mathbf{0 , 4 3}$ & 0,37 & 1 & $\mathbf{0 , 4 0}$ & $\mathbf{0 , 2 0}$ & 0,04 \\
\hline II. Почвенный воздух/Soil air & & 1 & 0,36 & 0,35 & & 1 & 0,56 & 0,42 & & 1 & $\mathbf{0 , 3 0}$ & 0,25 \\
\hline III. Почвы/Soils & & & 1 & 0,87 & & & 1 & $\mathbf{0 , 8 2}$ & & & 1 & $\mathbf{0 , 3 8}$ \\
\hline IV. Коренные породы/Bedrock & & & & 1 & & & & 1 & & & & 1 \\
\hline
\end{tabular}

Примечание: выделены значимые коэффициенты парной корреляции на уровне 0,05.

Note: significant pair correlation coefficients at the level of 0,05 are highlighted.

Отмеченные тесные связи концентраций ртути в объектах природной среды указывают на их сопряженный характер и на превалирование природных источников ее эмиссии в окружающую среду региона. Следует отметить, что на участках наложенного ртутного загрязнения промзон ГДП отсутствуют связи между содержанием ртути в горных породах и депонирующих ее природных средах.

Региональный геохимический фон ртути в природных средах. Полученные данные позволяют предварительно оценить региональный фон ртути в горных породах и компонентах природной среды на территории РА следующими значениями (табл. 8).

Таблица 8. Региональный геохимический фон ртути в компонентах природной среды

Table 8. Regional geochemical background of mercury in rocks and natural environments

\begin{tabular}{|c|c|c|c|c|c|c|c|c|}
\hline \multirow{2}{*}{$\begin{array}{c}\text { Кларки, фоны, ПДК (ОДК) } \\
\text { Clarks, backgrounds, } \\
\text { MPC (APC) }\end{array}$} & \multirow{2}{*}{$\begin{array}{c}\text { Земная } \\
\text { кора, мг/кг } \\
\text { Earth's crust, } \\
\mathrm{mg} / \mathrm{kg}\end{array}$} & \multirow{2}{*}{ 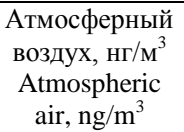 } & \multirow{2}{*}{$\begin{array}{l}\text { Почвы, } \\
\text { мг/кг } \\
\text { Soils, } \\
\mathrm{mg} / \mathrm{kg}\end{array}$} & \multicolumn{2}{|c|}{$\begin{array}{c}\text { Воды, мкг/дм }{ }^{3} \\
\text { Waters, } \mathrm{mcg} / \mathrm{dm}^{3} \\
\end{array}$} & \multirow{2}{*}{$\begin{array}{c}\text { Донные } \\
\text { отложения, мг/кг } \\
\text { Bottom sediments, } \\
\text { mg/kg }\end{array}$} & \multicolumn{2}{|c|}{$\begin{array}{l}\text { Растения } \\
\text { Plants } \\
\end{array}$} \\
\hline & & & & $\begin{array}{l}\text { речные } \\
\text { river }\end{array}$ & $\begin{array}{l}\text { подземные } \\
\text { underground }\end{array}$ & & 1 & 2 \\
\hline Кларк/Clarks [24] & 0,065 & 1,7 & 0,06 & 0,07 & 0,01 & 0,07 & \multicolumn{2}{|c|}{0,015} \\
\hline $\begin{array}{l}\text { Фон Сибири } \\
\text { Siberia background }\end{array}$ & 0,05 & $1-11$ & 0,04 & 0,02 & 0,02 & 0,07 & \multicolumn{2}{|c|}{$\begin{array}{l}\text { нет данных } \\
\text { no data }\end{array}$} \\
\hline $\begin{array}{l}\text { Фон Горного Алтая } \\
\text { Gorny Altai background }\end{array}$ & 0,10 & 4,0 & $\mathbf{0 , 1 1}$ & 0,10 & 0,04 & 0,10 & 0,017 & $\mathbf{0 , 0 2 0}$ \\
\hline $\begin{array}{l}\text { ПДК (ОДК, МДУ) } \\
\text { МРС (АРС, МРС) }\end{array}$ & - & 300 & 2,1 & 0,05 & 0,5 & - & $(0,05)$ & - \\
\hline
\end{tabular}

1 -разнотравье; 2 -листья тополя и березы; прочерк-отсутствие регламентов.

1 - motley grass; 2 - poplar and birch leaves; dash-lack of regulations.

В качестве комментария по достоверности оценки приведенного регионального фона ртути отметим следующее. Исходные, репрезентативные по объему выборок, данные для их расчета охватывали, как правило, весь регион и были получены (выбраны) для его незагрязненных фоновых по ртути территорий. При расчете фоновых значений были также использованы оценки регионального, а для отдельных районов - и локального геохимического фона, содержащиеся в опубликованных и фондовых материалах экологогеохимических работ в РА и на сопредельных территориях.

Сопоставление предварительно намеченного регионального геохимического фона ртути на территории региона с кларками земной коры, приземной атмосферы, гидро-, педо- и биосферы однозначно указывает на небольшое (в среднем в 1,5 раза), но устойчивое превышение «ртутного фона» Горного Алтая над кларковыми значениями и региональными фонами Сибири [22-25].

По нашему мнению, это обстоятельство обусловлено главным образом широким распространением в РА проявлений ртути и объектов ее разведки, разра-

\section{СПИСОК ЛИТЕРАТУРЫ}

1. Иванов В.В. Экологическая геохимия элементов: справочник. В 6 кн. / под ред. Э.К. Буренкова. Кн. 5: Редкие d-элементы. М.: Экология, 1997. - 576 с. ботки и применения, а также высоким миграционным потенциалом ртути в условиях резко расчлененного рельефа и высокой обводненности региона, способствующих ее активному распространению в объектах природной среды.

\section{Выводы}

1. Геологические образования Республики Алтай в целом не специализированы на ртуть, но на локальных участках ртутного оруденения проявлено ее слабо повышенное присутствие в компонентах природной среды.

2. Аномально повышенные уровни ртутного загрязнения компонентов природной среды обусловлены главным образом экологическими последствиями ее добычи и применения.

3. Современная хозяйственная деятельность в регионе не создает опасного загрязнения ртутью компонентов природной среды, но в его пределах существует ряд ранее сформированных техногенных источников эмиссии ртути, основными из которых являются отходы горнодобывающих предприятий.

2. Янин Е.П. Ртуть в окружающей среде промышленного города. - М.: ИМГРЭ, 1992. - 169 с.

3. Распределение ртути в компонентах окружающей среды горнорудных районов Республики Алтай / Д.В. Юсупов, Ю.В. Робертус, Л.П. Рихванов, Р.В Любимов., Е.Е. Ляпина, 
Е.М. Турсуналиева // Оптика атмосферы и океана. - 2018. T. 31. - № 1. - C. 73-78.

4. Геология и генезис ртутных месторождений Алтае-Саянской области / В.А. Кузнецов, В.И. Васильев, А.А. Оболенский, И.П. Щербань / отв. ред. акад. В.А. Кузнецов. - Новосибирск: Наука, 1978. - 295 c.

5. Робертус Ю.В. Масштабы и последствия применения ртути при золотодобыче в Республике Алтай // Экология и промышленность России. - 2020. - № 7. - С. 42-47.

6. Криночкин Л.А. Комплексная ресурсно-экологическая оценка территорий на примере многоцелевого геохимического картирования масштаба 1:1000000 (на примере южной части Алтайского края): дис. ... канд. геол.-минерал. наук. - М. ИМГРЭ, 1999. - 190 с.

7. Мальгин М.А., Пузанов А.В. Ртуть в почвах, почвенном и приземном воздухе Алтае-Саянской горной области // Химия в интересах устойчивого развития. - 1995. - Т. 3. - № 1-2. C. $161-173$.

8. Катунь: экогеохимия ртути / под ред. Н.А. Рослякова, А.Н. Дмитриева. - Новосибирск: ОИГГиМ, 1992. - 180 с.

9. Поведение ртути и других тяжелых металлов в экосистемах: аналитический обзор. Ч. 3. - Новосибирск: ГПНТБ СО АН CCCP, 1989. - 204 c

10. Папина Т.С., Артемьева С.С., Темерев С.В. Особенности миграции ртути в бассейне р. Катуни // Водные ресурсы. 1995. - T. 22. - № 1. - С. 60-66.

11. Гусев А.И., Топоркова Н.И., Вдовина Е.Ю. Экологогеохимическое районирование почв Алтае-Саянской складчатой области // Известия Алтайского отдела Русского географического общества. - 2015. - № 1 (36). - С. 95-101.

12. Озерова Н.А. Ртуть и эндогенное рудообразование. - М. Наука, 1986. - 232 с.

13. Формы нахождения и переноса ртути в компонентах экосистем Горного Алтая / Ю.В. Робертус, Л.П. Рихванов, Д.В. Юсупов, Р.В. Любимов, Е.Е. Ляпина, Н.А. Осипова // Химия в интересах устойчивого развития. - 2018. - № 2. - С. 185-192.

14. Робертус Ю.В., Рихванов Л.П. Химические элементы и вещества - индикаторы загрязнения природной среды Республики Алтай // Известия ТПУ. Инжиниринг георесурсов. - 2020. T. 331. - № 8. - C. 154-165.
15. Evaluation of mercury pollution in cultivated and wild plants from two small communities of the Tapajos gold mining reserve, Para State, Brazil / S.G. Egler, S. Rodrigues-Filho, R.C. Villas-Boas, C. Beinhoff // Sci. Total Environ. - 2016. - V. 368. - P. 424-433.

16. Distribution and mobility of mercury in soils of a gold mining region, Cuyuni river basin, Venezuela / F. Santos-Francés, A. García-Sánchez, P. Alonso-Rojo, F. Contreras, M. Adams // Journal of Environmental Management. - 2011. - V. 92. P. $1268-1276$.

17. Kabata-Pendias A. Trace elements in soils and plants. fourth ed. Boca Raton: CRC Press, 2011. - 505 p.

18. Malikova I.N., Anoshin G.N., Badmaeva Zh.O. Mobile mercury species in soils of natural and natural-technogenic landscapes // Rus. Geol. Geophys. - 2011. - V. 52. - P. 320-332.

19. Mercury uptake into poplar leaves / M. Assad, J. Parelle, D. Cazaux, F. Gimbert, M. Chalot, F. Tatin-Froux // Chemosphere. 2016. - V. 146. - P. 1-7.

20. Bargagli R. Moss and lichen biomonitoring of atmospheric mercury: a review // Science of the Total Environment. - 2016. V. 572. - P. 216-231.

21. Heavy metals accumulation in tree leaves from urban areas / M. Tomasevic, S. Rajsic, D. Dordevic, M. Tasic, J. Krstic, V. Novakovic // Environmental Chemistry Letters. - 2004. V. 2. - P. $151-154$

22. Григорьев Н.А. Распределение химических элементов в верхней части континентальной коры. - Екатеринбург, УрО РАН, 2009. $-383 \mathrm{c}$.

23. Страховенко В.Д., Маликова И.Н., Щербов Б.Л. Распределение ртути в компонентах окружающей среды Сибири // Химия в интересах устойчивого развития. - 2012. - Т. 20. - № 1. C. 117-123.

24. Assessment of mercury content in poplar leaves of Novokuznetsk agglomeration / E.E. Lyapina, D.V. Yusupov, E.M. Tursunalieva, V.V. Osipova // Conference Series: Earth and Environmental Science. - 2016. - V. 48 (1). - 012022.

25. Populus nigra $\mathrm{L}$. as a bioindicator of atmospheric trace element pollution and potential toxic impacts on human and ecosystem / A. Yalaltdinova, J. Kim, N. Baranovskaya, L. Rikhvanov // Ecological Indicators. - 2018. - V. 95. - P. 974-983

Поступила 01.03.2021 2.

\section{Информация об авторах}

Робертус Ю.В., кандидат геолого-минералогических наук, ведущий научный сотрудник, Институт водных и экологических проблем СО РАН.

Рихванов Л.П., доктор геолого-минералогических наук, профессор отделения геологии Инженерной школы природных ресурсов, Национальный исследовательский Томский политехнический университет.

Пузанов А.В., доктор биологических наук, профессор, директор, Институт водных и экологических проблем $\mathrm{CO} \mathrm{PAH}$

$\boldsymbol{K a ц ~ B . E . , ~ в е д у щ и и ̆ ~ с п е ц и а л и с т , ~ А О ~ « А л т а и ̆ - Г е о » . ~}$ 
UDC 553.499:550.4:504.064(571.150)

\title{
MERCURY IN THE COMPONENTS OF NATURAL ENVIRONMENT OF THE ALTAI REPUBLIC
}

\author{
Yuriy V. Robertus 1 , \\ ariecol@mail.gorny.ru
}

Leonid P. Rikhvanov $^{2}$

Alexander V. Puzanov ${ }^{1}$, puzanov-aleksander@mail.ru

Valentina E. Katz ${ }^{3}$, altai.geo@yandex.ru

1 Institute for Water and Environmental Problems SB RAS,

1, Molodezhnaya street, Barnaul, 656038, Russia.

2 National Research Tomsk Polytechnic University, 30, Lenin avenue, Tomsk, 634050, Russia.

3 JSC «Altai-Geo»,

52, Zavodskaya street, Maima, 649100, Russia.

The relevance of the work is caused by the need to generalize extensive diverse information on the ecogeochemistry of mercury in natural environments and man-made objects of the Altai Republic.

The aim of the research is to collect and systematize data on the levels of mercury content in the components of the natural environment in the background and contaminated areas of the region.

Methods: study and analysis of published and stock materials of ecological and geochemical works on mercury carried out in 1980-2010 by scientific and industrial organizations in the territory of the Altai Republic.

Results. Data on the main natural and anthropogenic sources of mercury emissions in the region and the levels of mercury pollution of the natural environment in the zones of their impact are presented. For the first time, the levels of mercury content were estimated for a large complex of components of the natural environment. The predominance of background concentrations of mercury in them and their close relations with the rocks of the folded basement are shown. Altitudinal zoning in mercury distribution in the soils of natural landscapes is planned. The background of mercury in rocks and other components of the natural environment of the region were preliminarily estimated. Its level is slightly increased relative to the world's Clarks.

Conclusions. The geological formations of the region are not mercury-specific. The increased level of local superimposed mercury pollution of natural environments is mainly due to its past extraction and use. Mercury concentrations in polluted natural environments are closely related. The main sources of anthropogenic mercury emissions are stale waste from mining enterprises. Modern economic activity in the region does not create dangerous pollution of the natural environment.

\section{Key words:}

Altai Republic, mercury, natural environments, emission sources, content levels, imposed pollution, local and regional background.

\section{REFERENCES}

1. Ivanov V.V. Ekologicheskaya geokhimiya elementov: spravochnik Redkie d-elementy [Environmental geochemistry of elements: reference book. Rare d-elements]. Ed. by E.K. Burenkov. Moscow, Ekologiya Publ., 1997. 576 p.

2. Yanin E.P. Rtut v okruzhayushchey srede promyshlennogo goroda [Mercury in the environment of an industrial city]. Moscow, IMGRE Publ., 1992. 169 p.

3. Yusupov D.V., Robertus Yu.V., Rikhvanov L.P., Lyubimov R.V., Lyapina E.E., Tursunalieva E.M. Distribution of mercury in environmental components of mining regions of the Altai Republic. Optics of the atmosphere and ocean, 2018, vol. 31, no. 1, pp 73-78. In Rus.

4. Kuznetsov V.A., Vasiliev V.I., Obolensky A.A., Shcherban I.P. Geologiya i genezis rtutnykh mestorozhdeniy Altae-Sayanskoy oblasti [Geology and genesis of mercury deposits in the Altai-Sayan region]. Ed. by Acad. V.A. Kuznetsov. Novosibirsk, Nauka Publ., 1978. $295 \mathrm{p}$

5. Robertus Yu.V. Scales and consequences of mercury application in gold mining in the Altai Republic. Ecology and Industry of Russia, 2020, no. 7, pp. 42-47. In Rus.

6. Krinochkin L.A. Kompleksnaya resursno-ekologicheskaya otsenka territoriy na primere mnogotselevogo geokhimicheskogo kartirovaniya masshtaba 1:1000000 (na primere yuzhnoy chast Altayskogo kraya). Dis. kand. nauk [Complex resource and eco- logical assessment of territories on the example of multi-purpose geochemical mapping of scale 1:1000000 (on the example of the southern part of the Altai territory). Cand. Diss.]. Moscow, 1999. $190 \mathrm{p}$.

7. Malgin M.A., Puzanov A.V. Mercury in soils, soil and surface air of the Altai-Sayan mountain region. Chemistry for sustainable development, 1995, vol. 3, no. 1-2, pp 161-173. In Rus.

8. Katun: ekogeokhimiya rtuti [Katun: mercury ecogeochemistry]. Eds. N.A. Roslyakov, A.N. Dmitriev. Novosibirsk, UIGGM Publ., 1992. $180 \mathrm{p}$.

9. Povedenie rtuti $i$ drugikh tyazhelykh metallov v ekosistemakh: analiticheskiy obzor [Behavior of mercury and other heavy metals in ecosystems: analytical review]. Novosibirsk, SPSTL SB AS USSR Publ., 1989. 204 p.

10. Papina T.S., Artemyeva S.S., Temerev S.V. Features of mercury migration in the Katun river basin. Water resources, 1995, vol. 22, no. 1, pp. 60-66. In Rus.

11. Gusev A.I., Toporkova N.I., Vdovina E.Yu. Ecological and geochemical zoning of soils of the Altai-Sayan folded region. Izvestiya of the Altai Department of Russian geographical society, 2015, no. 1 (36), pp. 95-101. In Rus.

12. Ozerova N.A. Rtut i endogennoe rudoobrazovanie [Mercury and endogenous ore formation]. Moscow, Nauka Publ., 1986. $232 \mathrm{p}$

13. Robertus Yu.V., Rikhvanov L.P., Yusupov D.V., Lyubimov R.V., Lyapina E.E., Osipova N.A. Forms of finding and transferring mercury in the components of the ecosystems of the Altai Moun- 
tains. Chemistry for sustainable development, 2018, no. 2, pp. 185-192. In Rus.

14. Robertus Yu.V., Rikhvanov L.P. Chemical elements and substances-indicators of pollution of the natural environment of the Altai Republic. Bulletin of the Tomsk Polytechnic University. Geo Assets engineering, 2020, vol. 331, no. 8, pp. 154-165. In Rus.

15. Egler S.G., Rodrigues-Filho S., Villas-Boas R.C., Beinhoff C. Evaluation of mercury pollution in cultivated and wild plants from two small communities of the Tapajos gold mining reserve, Para State, Brazil. Sci. Total Environ, 2016, vol. 368, pp. 424-433.

16. Santos-Francés F., García-Sánchez A., Alonso-Rojo P., Contreras F., Adams M. Distribution and mobility of mercury in soils of a gold mining region, Cuyuni river basin, Venezuela. Journal of Environmental Management, 2011, vol. 92, pp. 1268-1276.

17. Kabata-Pendias A. Trace elements in soils and plants. fourth ed. Boca Raton, CRC Press, 2011. 505 p.

18. Malikova I.N., Anoshin G.N., Badmaeva Zh.O. Mobile forms of mercury in soils of natural and natural-technogenic landscapes. Geology and Geophysics, 2011, vol. 52, no. 3, pp. 409-425.

19. Assad M., Parelle J., Cazaux D., Gimbert F., Chalot M., TatinFroux F. Mercury uptake into poplar leaves. Chemosphere, 2016, vol. 146, pp. 1-7.

20. Bargagli R. Moss and lichen biomonitoring of atmospheric mercury: a review. Science of the Total Environment, 2016, vol. 572, pp. 216-231.

\section{Information about the authors}

Yuriy V. Robertus, Cand. Sc., leading researcher, Institute for Water and Environmental Problems SB RAS.

Leonid P. Rikhvanov, Dr. Sc., professor, Department of geology, Engineering School of Natural Resources, National Research Tomsk Polytechnic University.

Alexander V. Puzanov, Dr. Sc., professor, director, Institute for Water and Environmental Problems SB RAS.

Valentina E. Katz, leading researcher, JSC «Altai-Geo».
21. Tomasevic M., Rajsic S., Dordevic D., Tasic M., Krstic J., Novakovic V. Heavy metals accumulation in tree leaves from urban areas. Environmental Chemistry Letters, 2004, vol. 2, pp. 151-154.

22. Grigoriev N.A. Raspredelenie khimicheskikh elementov v verkhney chasti kontinentalnoy kory [Distribution of chemical elements in the upper part of the continental crust]. Yekaterinburg, Ural Branch of the Russian Academy of Sciences Publ., 2009. 383 p.

23. Strahovenko V.D., Malikova I.N., Shcherbov B.L. distribution of mercury in components of the Siberian environment. Chemistry for sustainable development, 2012, vol. 20, no. 1, pp. 117-123. In Rus.

24. Lyapina E.E., Yusupov D.V., Tursunalieva E.M., Osipova V.V. Assessment of mercury content in poplar leaves of Novokuznetsk agglomeration. Conference Series: Earth and Environmental Science, 2016, vol. 48 (1), 012022.

25. Yalaltdinova A., Kim J., Baranovskaya N., Rikhvanov L. Populus and potential toxic impacts on human and ecosystem. Ecological Indicators, 2018, vol. 95, pp. 974-983.

Received: 1 March 2021. nigra $\mathrm{L}$. as a bioindicator of atmospheric trace element pollution 